\title{
O CONCEITO DE TECNOLOGIA E OS MOVIMENTOS SOCIAIS NA ERA DA INTERNET
}

\section{Conrado Pereda Minucelli ${ }^{i}$}

\begin{abstract}
Resumo: Com o objetivo de tratar de duas das principais características que envolvem os padrões emergentes de ação coletiva no espaço público no século XXI - a tecnologia e a Internet - o presente artigo, por meio de uma discussão teórica e conceitual, desenvolve o conceito de tecnologia numa perspectiva crítica, analisando seus possíveis lugares no processo histórico político brasileiro que culminou nos importantes ciclos de protestos massificados de Junho de 2013 no país. Analisando este contexto, abordam-se ainda os aspectos ideológicos, de representações coletivas e de construção da autonomia do ativismo cibernético e suas relações com o Estado e a sociedade.
\end{abstract}

Palavras-chave: Tecnologia; Movimentos sociais em rede; Internet.

\begin{abstract}
With the objective of dealing with two of the main characteristics that involve the emerging patterns of collective action in public space in the $21^{\text {st }}$ century - technology and the Internet - this article through a theoretical and conceptual discussion, develops the concept of technology in a critical perspective, analyzing its possible places in the Brazilian political and historical process that culminated in the important cycles of mass protests of June 2013 in the country. Analyzing this context, are addressed the ideological aspects of colletive representations and the construction of the autonomy of cyber activism and its relations with the State and society. Key words: Technology; Social network movements; Internet.
\end{abstract}

\section{Introdução}

A lógica da industrialização e da tecnologização das relações sociais e políticas é fenômeno presente desde a Revolução Industrial inglesa, expoente do surgimento da organização social capitalista, mas é na década de 1970, com o advento da Internet e suas possibilidades de comunicação globalizada, que a tecnologia passa a ser usada como forma de, em certa medida, democratizar os debates políticos e o controle social sobre o Estado, especialmente com o uso das tecnologias da informação em rede pelos movimentos de contracultura emergentes à época.

Não há como garantir, neste aspecto, a determinação do uso das Tecnologias da Informação e Comunicação (TIC's) conforme o crescimento do sistema econômico capitalista, pois os avanços tecnológicos se mostraram muito segmentados e orientados para fins diversos, mas o conteúdo presente nas redes pode ser considerado como determinantemente influenciado pelas disputas de posições políticas dos movimentos sociais e suas pautas (Castells, 1999).

Neste sentido, a criação das chamadas comunidades virtuais de mobilização em rede, soam como resposta à crescente desvinculação social causada pela virtualização da vida, como forma de produção e reprodução cultural de códigos e identidades individuais no sentido da autonomia da comunicação entre os indivíduos. Esta nova morfologia social acaba por modificar, portanto, a 
operação e os resultados das experiências sociais dos indivíduos com a política, com o poder e com os sistemas culturais.

O capitalismo e todas as suas consequências, enquanto sistema cultural e econômico, parece se caracterizar como um dos principais oponentes, por vezes não declarado, dos novos movimentos sociais, devido à amplitude das pautas econômicas colocadasii ${ }^{\mathrm{ii}}$. Porém, o próprio capitalismo apropriou-se do novo contexto de comunicação e inovação para enfim modificar também seu modo de operação, tornando-se um sistema cada vez mais descentralizado e poderoso. Ainda de acordo com o sociólogo espanhol, as

redes são instrumentos apropriados para a economia capitalista baseada na inovação, globalização e concentração descentralizada; para o trabalho, trabalhadores e empresas voltadas para a flexibilidade e adaptabilidade; para uma cultura de desconstrução e reconstrução contínuas; para uma política destinada ao processamento instantâneo de novos valores e humores públicos; e para uma organização social que vise a suplantação do espaço e invalidação do tempo (CASTELLS, 1999, p. 566)

Portanto, o tipo de sociedade em que se inserem os movimentos em rede é a sociedade em rede capitalista, globalmente estruturada, com uma rede de fluxos financeiros especulativos bem consolidada e arriscada, e investimentos de desenvolvimento tecnológicos para o seu avanço e maior consolidação.

Para isto, a criação do conceito de mercado financeiro, no qual o investimento é grande e arriscado, mas a produção de bens para a sociedade é pífia, foi fator preponderante para o surgimento de duas categorias: 1) o crescimento do desemprego estrutural nos países europeus e o crescimento da desigualdade social entre ricos e pobres, além da cristalização de uma camada social de riqueza isolada do restante da população produtiva, em que os perdedores pagam pelos ganhadores e; 2) a resposta à primeira categoria, pelos movimentos sociais em rede, através de grandes mobilizações virtuais e, posteriormente presenciais, para o questionamento deste tipo de sistema econômico e do poder institucionalizado.

As consequências desta construção social passam, por exemplo, pela constituição de uma nova camada de capitalistas, chamados por Castells (1999) de capitalistas sem rosto, ligados exclusivamente ao fluxo de informações virtuais e ao risco especulativo financeiro, com reflexo recíproco na classe trabalhadora, ou seja, novas características surgem emersas também na possibilidade de não identificação pessoal da maioria da população, por meio das redes sociais.

Eis o principal tema identitário de um movimento formado por pessoas que não se identificam pessoalmente, mas sim com o uso de máscaras de um famoso conspirador inglês, conhecido como Guy Fawkes (1570 - 1606), e que, por meio deste instrumento, procuram representar uma ideia de contravenção sistêmica. Estes se autodenominaram Anonymous. 
Constituídos na forma de uma comunidade online desde o ano de 2003, esta articulação de pessoas atua de forma anônima contra o sistema político, segmentada ou globalmente, sendo decisiva para a grande popularidade dos protestos entre a juventude, destacadamente em relação à ideia de liberdade, autonomia e subversão da ordem que a máscara e o próprio movimento representam.

De acordo com Castells (2013), os movimentos em rede são, portanto, novas formas de indignação social e de movimentos sociais que surgem para responder a crises do sistema político, sejam elas pontuais ou estruturais, mas principalmente estruturais. São movimentos também profundamente autorreflexivos, pois se questionam permanentemente presencial ou virtualmente por meio de debates em fóruns ou plenárias. Todas estas características são também envoltas da constituição da Internet e da tecnologia como grande plataforma de mobilização e mudança social em diversos contextos nacionais, tema que será tratado neste artigo.

\section{Tecnologia, protestos e comunidades virtuais de mobilização em rede no Brasil}

Indignar-se foi, nos padrões rígidos de sociabilidade das sociedades do início do século XX (de relações sociais ainda mecanizadas, resquícios das profundas mudanças do século XIX), um ato transgressivo, a ser repelido e evitado pelos sistemas políticos. O século das revoluções, portanto, foi também o século das contrarrevoluções.

Isto não significa que os paradigmas mudaram na virada do século. A repressão e coerção física do monopólio legítimo do uso da força do Estado continuam defendendo as cercas que dividem as aspirações revolucionárias, dos interesses políticos das classes representativas.

A propósito disto, a modernidade lançada pelo século XIX, como um tempo histórico de intensas mudanças de paradigmas, ou uma passagem de uma razão instrumental e um coletivismo latente para um individualismo e uma desvinculação das ideias de grupo, classe e de sociedade; trouxe, para as sociedades ocidentais, o grande desafio de desenvolver-se em consonância com os interesses e paixões individuais, dada a importância fundamental que passam a ter os direitos individuais.

Neste ponto, existiu ainda uma grande permanência das antigas formas de relações, pois a maioria das expressões de modernização foi dada através da subordinação de alguns países a um poder colonial que aumentou a distância entre as elites ocidentais e os povos tradicionais ou de resistência à modernidade, criando uma espécie de modernização conservadora (Touraine, 2011).

Esta colonização ou modernização conservadora acabou por impor aos movimentos de indignação alguns impeditivos de ordem prática, como a desmobilização dos indivíduos incentivada 
pelo Estado e seu aparato e, de ordem moral, cristalizando a indignação como umas das formas de expressão de possíveis histerias sociais a serem repelidas e exterminadas.

A introdução da tecnologia neste contexto surge como elemento novo ao se constatar que as tecnologias de poder e coerção mecânicas passavam, gradativamente, a tomar formas virtuais, mantendo do mesmo modo suas características de biopoder e, ao mesmo tempo, passando a exigir cada vez mais respostas dos indivíduos, grupos e do Estado formas de disputa por essa nova arena do espaço público.

É sobre aquela colonização e para os países subalternados atingidos pela modernização e suas consequências tecnológicas e sociais que Álvaro Vieira Pinto (2009) descreve seu conceito de tecnologia, mesclando uma análise filosófica da técnica e da tecnologia, com a defesa de um tipo de descolonização destes países, por meio da função social de análise e crítica de intelectuais e pensadores sobre o assunto.

Desse modo, o autor parte do pressuposto que o salto qualitativo e ontológico que realiza o ser humano com a criação e o emprego da técnica, delimita a ação individual como determinantemente relacionada ao meio em que se aplicam tais instrumentos. Em outras palavras, o emprego das tecnologias e seus fins comerciais e também políticos passam a ser entendidos como repercussões de uma realidade dada social e historicamente.

Por este modo, a prática da técnica conduz à modificação das idéias, podendo alterar as existentes, anulá-las ou introduzir outras, novas. Representa portanto inequívoco fator de constituição de conteúdo da consciência individual, modelada pela realidade social, em consequência do modo segundo o qual é recebida pelo conjunto da atividade de cada elemento pessoal (PINTO, 2009, p. 321).

Deste prisma, não se pode dissociar a existência das comunidades virtuais da necessidade social a que elas se destinam e, nem dissociá-las da existência concreta dos indivíduos, que as utilizam dos mais variados modos. As necessidades para que se (re)produzam são diretamente relacionadas, portanto, ao grande e constante processo de virtualização da vida política, da mobilidade humana e da necessidade premente de liberdade de expressão trazida pelos direitos e liberdades individuais.

As ideias individuais, ou a mudança de paradigmas em relação à tecnologia, passam a encarar as redes sociais e a Internet de modo geral, como um meio de autopromoção de direitos, de liberdade e adequação a tantas quantas forem as necessidades de consumo e de expressão simbólica e real trazidas pelo sistema capitalista e suas consequências.

Nesse sentido, as técnicas, as tecnologias e seus produtos não são isentos de um processo de ideologização programada pelo sistema social. O mais simples uso de equipamentos importados, por exemplo, caracteriza não só a cultura do país exportador como superior à do importador, como também carrega simbologias e ideias de consumo e de realização que só podem ser contempladas 
com aquele produto e suas constantes atualizações, todas produzidas naquele país. Isto acaba por gerar um rebaixamento da cultura local e a noção de que a "boa" tecnologia só se faz fora dali (Pinto, 2009).

A grande proposta a que se recorre aqui é tratar os resultados do emprego tecnológico e da própria produção da técnica, como a utilização das redes virtuais para a organização ou manutenção de manifestações políticas, como passíveis também de influências históricas e sociais que fogem da regra individual da escolha por este ou aquele perfil político de manifestação, do uso ou não de determinadas formas de organização ou de protesto e até mesmo da definição desta ou daquela ideologia política a seguir, mesmo porque estes movimentos não se pretendem definidos, ou seja, a regra é a indefinição.

Cabe aqui ressaltar que, além das orientações individuais gerais e do comportamento político dos cidadãos, são as necessidades reais e, portanto, históricas e sociais das comunidades que levam à mobilização política. Do mesmo modo, admitindo que os movimentos sociais na era da Internet ainda guardam uma relação indefinida com a ideologia política em seus conceitos filosóficos e sociológicos clássicos, não se pode considerar apenas um dos dois primas de análise, sob pena de se incorrer no ocultamento de variáveis importantes.

Considerando estas influências, a disputa ideológica realizada pela mídia hegemônica e pelas diferentes organizações políticas institucionais ou não sobre os protestos de Junho de 2013 no Brasil, podem ser entendidas como uma expressão da realidade polarizada politicamente em que se encontrava o Brasil e os países que sofrem das crises econômicas mundiais cada vez mais recorrentes.

A disputa também sobre a juventude e seus rumos colocou aos partidos e à institucionalidade política o desafio de satisfazer os anseios das ruas, readaptando práticas e formas pelas quais operavam. Dado disto é a rápida e pública resposta governamental, nos âmbitos municipal, estadual e federal às grandes manifestações que pediam por mais saúde, educação, transporte público e o fim corrupção.

Apesar da pouca eficácia desta resposta até os dias atuais, o fato de ela ter sido dada em um período ao mesmo tempo curto - acompanhando o fluxo das redes - mas com aplicação distante, demonstra que disputar ideologicamente os rumos e as características dos protestos era tarefa primordial para a não desestabilização política do país e da constituição atual do Poder Executivo e Legislativo (Minucelli, 2015).

Assim, além das respostas de governos municipais e estaduais por meio da redução de impostos sobre empresas de transporte coletivo para redução de tarifas, o Governo Federal também lançou, em cadeia nacional de TV e rádio, cinco eixos fundamentais de tentativas de mudança referentes às reivindicações: 1) Responsabilidade fiscal e controle da inflação; 2) Plebiscito para formação de uma constituinte sobre reforma política; 3) Saúde; 4) Educação e 5) Transportes. 
As tentativas esbarraram na forma de governabilidade praticada pelo então Governo Federal e, tiveram no Congresso Nacional interpretações diferentes, culminando em 2015 em propostas por vezes diferentes das reivindicadas majoritariamente nas ruas, como a redução da maioridade penal e uma minirreforma eleitoral ${ }^{\mathrm{iii}}$.

Além disto, nota-se também na intensa cobertura midiática dos protestos, uma disputa ideológica pelo lugar e pelos graus de violência e sua estética nas manifestações. Essa disputa envolveu não apenas a rede televisiva, como também os grandes e pequenos jornais e conglomerados tradicionais da comunicação, que passaram a tecer análises rápidas sobre cada passo dos protestos, praticamente em tempo real.

O que se pode perceber é que, como afirma Pinto (2009), a tecnologia não é somente produção de equipamentos para a utilização neutra do destinatário, mas sim um instrumento ideológico de dimensão política, que pode caminhar por variados passos: incentivar, colocar na apatia, entusiasmar ou entristecer. Conceber os movimentos em rede desta forma nos permite compreender com mais evidência as múltiplas possibilidades que a ideologia, as visões de mundo e que a própria tecnologia dão à modernidade. Em suma, a inserção dos movimentos em rede na chamada era tecnológica é, essencialmente, uma produção também ideológica, portanto, sem uma neutralidade política definida.

Contudo, não é possível separar este tipo de modernização, dos comportamentos individuais que levam a sociedade do século XXI a uma comunicação individual autônoma para a crítica ao seu sistema político ou sua representação política, pois a individualização das referências sociais e, portanto, políticas, permitem que se abra nos seios das sociedades imensas crises de representação. Essas crises são abertas pela intensa criação de novos paradigmas de visão do mundo político, que acabam por enaltecer e fazer crescer as críticas aos sistemas representativos e a suas falhas específicas.

Defende Castells (2013) que, ainda que as forças do Estado - órgão que mantém as classes representativas - reprimam a indignação nos dias de hoje, um sistema político age também na criação de significados no imaginário dos indivíduos, o que facilita a dominação e a prática dos projetos de poder. Este paradigma segue a lógica da modernização, substituindo as ações em torno do social e do coletivo, para ação sobre o indivíduo ou sobre os sujeitos e atores.

Esta construção de significados sociais é, para os movimentos sociais de hoje, processo constitutivo de uma sociedade que se moderniza e muda no sentido da autonomia da comunicação entre os indivíduos. Sendo assim, o poder da comunicação numa sociedade em rede, ou seja, em uma sociedade que estabelece laços individuais em diversos âmbitos da vida social, é fundamental para se entender o porquê de a indignação tomar as ruas e causar a repressão com tamanha força e rapidez. 
Construir significados para a prática coletiva não significa apenas incentivar ou fomentar a criação de redes políticas no imaginário social, mas sim agir sobre o comportamento humano, modificando as concepções de estrutura e formatação das atitudes dos cidadãos, concepção que evidencia que:

\begin{abstract}
Ao longo da história, os movimentos sociais são produtores de novos valores e objetivos em torno dos quais as instituições da sociedade se transformaram a fim de representar esses valores criando novas formas para organizar a vida social. Os movimentos sociais exercem o contrapoder construindo-se, em primeiro lugar, mediante um processo de comunicação autônoma, livre do controle dos que detêm o poder institucional. Como os meios de comunicação de massa são amplamente controlados por governos e empresas de mídia, na sociedade em rede a autonomia de comunicação é basicamente construída nas redes da Internet e nas plataformas de comunicação sem fio. As redes sociais digitais oferecem a possibilidade de deliberar sobre e coordenar as ações de forma amplamente desimpedida (CASTELLS, 2013, p. 18)
\end{abstract}

É imperativo considerar que a contestação ao poder, em seu sentido literal, se difunde com muito mais intensidade neste contexto, formando uma multidimensional organização em torno de redes dos mais diversos domínios das atividades dos indivíduos, inclusive os mais pessoais e/ou profissionais, de acordo com valores e interesses diversos. Para isso, as redes sociais de comunicação em massa autônomas, livres do editorial de imprensa, estabelecem novos olhares e formatos às instituições políticas.

Para além da Internet, os espaços urbanos também são ocupados, compreendendo que é fundamental para a existência dos movimentos sociais a sua materialização, ou seja, sua manifestação real nas ruas e no espaço público. Assim, os espaços urbanos ocupados pelos movimentos em rede desempenham, além do já exposto, um importante componente na história da mudança social, proporcionando à prática contemporânea dos movimentos sociais possibilidades como: 1) a criação de comunidades de proximidade; 2) maior poder simbólico ao movimento social e 3) a construção de espaços políticos híbridos entre as redes sociais da Internet e o espaço urbano ocupado (Castells, 2013).

Tais características contribuem como elementos essenciais para a vida e manutenção dos movimentos sociais, uma vez que as comunidades de proximidade são mecanismos fundamentais para a superação do medo da ação coletiva, ao passo que, ao se juntar a uma área ocupada pelo movimento social, outros e mais cidadãos podem participar do movimento sem estar ligado a alguma ideologia política ou organização burocrática, mas sim, por seus próprios motivos.

Ainda assim, uma vez ocupando áreas em que o poder do Estado domina, os movimentos em rede geralmente conseguem representar que a ocupação simboliza a reivindicação do uso do espaço público e o querer por uma democracia real, ou apenas por democracia. Este controle coletivo do espaço, acima de tudo, também representa o controle das vidas das pessoas, podendo, 
com a construção de espaços híbridos de atuação política, transformarem-se em comunidades instantâneas de prática transformadora, livres dos interesses dominantes.

Compreender esses movimentos, suas práticas, modos de operação e sua presença inédita no cenário brasileiro passam necessariamente por compreender os contextos políticos, a situação geracional dos operadores da tecnologia e das redes e a forma como todos esses elementos confluem para a materialização dos anseios democráticos.

\section{Breves considerações finais}

Refletindo acerca das relações entre a juventude nas mobilizações de Junho de 2013, a tecnologia construída e empregada socialmente nas redes sociais e, os recentes ciclos de protestos brasileiros, percebe-se que, imbuídos dessa ferramenta e conscientes ou não das possibilidades que as comunidades virtuais e as Tecnologias da Informação e Comunicação podem proporcionar aos fins que desejavam os indivíduos, buscou-se e ainda busca-se, de forma horizontal, democrática e reflexiva, utilizar a multimodalidade e funcionalidade desidentificadora das tecnologias para, empoderados do sentimento de relevância social e da certeza de que somente a participação muda os rumos políticos, reivindicar mudanças no sistema político e econômico.

Desta forma, as comunidades democráticas se proliferaram no ambiente virtual mundial e, aos poucos, alcançaram proporções gigantescas de impacto sobre todos os usuários da rede. Tal magnitude, no Brasil, se expressou materialmente em protestos físicos em várias cidades, agindo inclusive sobre locais em que a cultura de protestos de rua era parca e os indivíduos razoavelmente desmotivados pelas características tradicionais da política a manifestarem posições no espaço público de forma organizada.

Campo privilegiado de manifestações de posições políticas, as redes virtuais e os protestos físicos, neste contexto, passaram a replicar informações, textos, imagens, poesias e opiniões que davam a certeza de que a mudança viria com a adesão de um contingente maior de indivíduos dispostos a trazerem as suas reivindicações locais e pessoais. Deste modo, a mescla ideológica e a diversidade das pautas gerada levaram a uma dualidade de informações e pensamentos sobre aqueles que seriam, inicialmente, os objetivos das manifestações, sem, no entanto, retirar delas a legitimidade que os próprios movimentos conquistaram junto à sociedade brasileira.

Assim, os movimentos em rede passaram a ser parte integrante do complexo e amplo conceito de tecnologia, que toma dimensões de importância elevada no cenário político, social e econômico e, que dotados da disputa ideológica de posições sobre visões de mundo e da política, demonstraram que não são politicamente neutros. 
Como uma nova forma de arranjo dos significados e práticas culturais, a cibercultura também se consolidou como um momento inédito na história dos movimentos sociais reivindicatórios, por meio de um desejo coletivo expresso de maneira rápida e impactante e de um programa virtual de interconexão entre os cidadãos, aprimorando a inteligência coletiva e cristalizando as comunidades virtuais como canais de participação relevantes para os sistemas políticos.

Desta forma, além das mudanças de paradigmas conquistados pela modernidade com relação à maior democratização das relações políticas, o ciberespaço, as cidades e a democracia eletrônica constituem gradualmente novos paradigmas na intermediação entre os indivíduos e a política institucional ou não institucional. Esses elementos são, assim como as redes sociais, as formas pelas quais a modernidade procura se articular com a participação política e o controle social.

Diante da possibilidade da comunicação autônoma baseada nas redes, que configurou uma cultura de autonomia em relação à institucionalidade e às formas tradicionais de se fazer política, esses novos movimentos sociais trouxeram ao campo dos movimentos sociais um aparente padrão emergente de ação coletiva que, sustentados na grande crise de representatividade política, imprimiu e imprime novos horizontes ao questionamento dos sistemas políticos, procurando aprimorar e aprofundar a participação democrática, mas principalmente, redimensionando a noção de controle sobre os direitos sociais.

\section{Referências bibliográficas}

CASTELLS, Manoel. Redes de indignação e esperança: movimentos sociais na era da Internet. Rio de Janeiro : Zahar, 2013. . A sociedade em rede. São Paulo : Paz e Terra, 1999.

MINUCELLI, Conrado. P. 2015. Participação, cultura e socialização política juvenil em Cascavel/PR: uma análise a partir dos movimentos em rede. Toledo, PR. Dissertação de Mestrado em Ciências Sociais. Universidade Estadual do Oeste do Paraná.

PINTO, Álvaro. V. O conceito de tecnologia. Rio de Janeiro : Editora Contraponto, Vols. I e II, 2009.

TOURAINE, Alain. Um novo paradigma: para compreender o mundo de hoje. $4^{\mathrm{a}}$ Ed. Petrópolis: Vozes, 2011. 
' Professor colaborador Assistente da Universidade Estadual do Oeste do Paraná (Unioeste), Campus de Cascavel. Mestre em Ciências Sociais e pesquisador do Grupo de Pesquisa em Comportamento Político (GPCP).

ii O movimento Occupy Wall Street, por exemplo, questionou de forma veemente o grande poder econômico e político do " $1 \%$ da população", em contraposição ao restante da maioria da população que não dispõe dos mesmos benefícios.

iii A minirreforma eleitoral aprovada pelo Congresso Nacional em 2015 se trata do Projeto de Lei (PL) 5735/13 e da Proposta de Emenda à Constituição (PEC) 182/2007, que apenas limitou gastos de doações de empresas a partidos políticos e campanhas eleitorais, modificou regras para tempo gratuito de TV, prestações de contas e quantidade de candidatos. 